\title{
Autonomic Neuropathy in the Skin: A Histological Study of the Sympathetic Nerve Fibres in Diabetic Anhidrosis
}

\author{
I. Faerman ${ }^{1}$, E. Faccio ${ }^{3}$, I.Calb ${ }^{2}$, J.Razumny ${ }^{1}$, N. Franco ${ }^{2}$, A. Dominguez ${ }^{2}$ and H.A. Podestá ${ }^{1}$ \\ ${ }^{1}$ Department of Medicine, Endocrine and Diabetes Section, ${ }^{2}$ Dermatology Section, Hospital Español and \\ ${ }^{3}$ Pathology Department, Borda Hospital, Buenos Aires, Argentina
}

\begin{abstract}
Summary. In diabetics with the anhidrotic syndrome, autonomic nerve fibres were studied in skin biopsies using argentic techniques and light microscopy. The Minor test was used to differentiate normal from anhidrotic skin areas. In the anhidrotic areas, histology of the nerve fibres showed beading, spindle-shaped thickening and fragmentation adjacent to the sweat glands. These changes were similar to those observed in two patients who had previously undergone lumbar sympathectomy. No abnormalities of the sympathetic nerve endings could be found in biopsies taken from normal areas of the forearm of the same patients. We conclude that the diabetic anhidrotic syndrome, a form of diabetic autonomic neuropathy, is due to a lesion of the sympathetic nerve supply to the skin. It is suggested that the Minor test or a skin biopsy should be performed in diabetic patients who are being considered for surgical sympathectomy.
\end{abstract}

Key words: Anhidrosis, sweat secretion, autonomic nerve fibre, sympathetic chain, Minor test, skin biopsy, argentic techniques, sympathectomy, diabetic visceral neuropathy.

Alterations in sweating are particularly common in diabetic patients with autonomic neuropathy [1]. The first reference to this anomaly was made by Pryce in 1893 [2], but it was Rundles who published the first clinical description in 1945 [3]. He found that 36 out of 125 patients with diabetic neuropathy had alterations in perspiration and he associated this change with other alterations of the autonomic nervous system, particularly changes in blood pressure and skin temperature. Similar descriptive clinical findings have been documented by several other authors $[4,5]$.

Physiological and histological research into changes in sweat production is difficult and this may have contributed to the scarcity of studies on this sub- ject. Normal patterns of sweat production have been determined by List and Peet [6] and by Hyndman and Wolkin [7]. Perhaps the most reliable methods include those described by Minor [8] which depends on the starch-iodine reaction, and the technique of Brown and Adson [9] in which strips of paper soaked with cobalt chloride are applied to the skin. Alternatively, quinarizine may be used, which turns blue on contact with skin moisture [10]. Most of these methods are relatively simple although less accurate than the determination of sweating by galvanic skin resistence techniques.

Although not specific, the symptoms suffered by diabetics from sweating disturbances are fairly typical [5]. Initially there is heat intolerance accompanied by hyperhidrosis of the upper half of the body, particularly affecting the face, neck, axillae and hands. It is of interest that these patients rarely perspire excessively below the umbilicus. This diabetic syndrome has been attributed to a lesion of the sympathetic nerve fibres which control sweat secretion [11] and follow the course of the peripheral nerves [12]. This affects the efferent branch of the reflex arch and is identical to that occurring distal to a surgical sympathectomy [13].

To investigate whether the diabetic anhidrosis syndrome may be due to a lesion of the sympathetic nerve fibres, we studied those fibres which control sweat secretion. First we used the Minor test [8] to confirm the presence of anhidrosis and then we performed skin biopsies to study nerve fibre histology, using established argentic techniques and light microscopy.

\section{Patients and Methods}

Eleven diabetic patients attending the Endocrinology clinic of the Hospital Español were studied. Their mean age was 61.5 years (range 51-72 years) and diabetes duration 12.8 years (range 7 
Table 1. Clinical features of the patients studied

\begin{tabular}{|c|c|c|c|c|c|c|c|c|c|c|}
\hline Patient & Sex & $\begin{array}{l}\text { Age } \\
\text { (years) }\end{array}$ & $\begin{array}{l}\text { Duration of } \\
\text { diabetes } \\
\text { (years) }\end{array}$ & Treatment & $\begin{array}{l}\text { Peripheral } \\
\text { vascular } \\
\text { disease }\end{array}$ & $\begin{array}{l}\text { Nephrop- } \\
\text { athy }\end{array}$ & $\begin{array}{l}\text { Reti- } \\
\text { nopathy }\end{array}$ & $\begin{array}{l}\text { Peripheral } \\
\text { neuropathy }\end{array}$ & Minor test & $\begin{array}{l}\text { Histological } \\
\text { findings }\end{array}$ \\
\hline 1 & M & 58 & 20 & OHA & Yes & Yes & No & Yes & Abnormal & Abnormal \\
\hline 2 & $M$ & 59 & 15 & $\mathrm{OHA}$ & Yes & No & Yes & Yes & Abnormal & Abnormal \\
\hline 3 & $\mathrm{~F}$ & 56 & 7 & $\mathrm{OHA}$ & No & No & No & No & Normal & Normal \\
\hline 4 & $\mathrm{M}$ & 71 & 30 & $\mathrm{OHA}$ & Yes & Yes & Yes & Yes & Abnormal & Abnormal \\
\hline 5 & $M$ & 56 & 7 months & $\mathrm{OHA}$ & No & No & No & No & Normal & Normal \\
\hline $6^{\mathrm{a}}$ & M & 67 & 10 & $\mathrm{OHA}$ & Yes & No & No & Yes & Abnormal & Abnormal \\
\hline 7 & $\mathrm{M}$ & 62 & 5 & $\mathrm{OHA}$ & Yes & Yes & No & No & Abnormal & Abnormal \\
\hline 8 & $\mathrm{M}$ & 72 & 16 & $\mathrm{OHA}$ & Yes & Yes & Yes & Yes & Abnormal & Abnormal \\
\hline 9 & $\mathrm{M}$ & 61 & 10 & $\mathrm{OHA}$ & No & Yes & Yes & Yes & Abnormal & Abnormal \\
\hline $10^{\mathrm{a}}$ & $\mathrm{M}$ & 64 & 23 & Insulin & Yes & Yes & Yes & Yes & Abnormal & Abnormal \\
\hline 11 & $\mathrm{M}$ & 51 & 5 & Insulin & No & No & No & No & Abnormal & Abnormal \\
\hline
\end{tabular}

OHA: Oral hypoglycaemic agents

${ }^{a}$ Previously sympathectomized patients

months -30 years). There were ten males and one female. Their clinical features are shown in Table 1 . Informed consent was obtained from all patients. Two of the 11 patients had previously undergone lumbar sympathectomy for peripheral vascular disease.

A Minor test was performed on the skin of the lower limbs and the flexor surface of a forearm with the patient recumbent. After staining the skin with 'Minor' mixture (iodine $1.5 \mathrm{~g}$, acetone $75 \mathrm{~g}$ and alcohol $75 \mathrm{~g}$ ) [8] starch powder was applied to the same areas very thinly.

To warm the skin, each patient was exposed to direct heat from six 40-watt lamps for $30 \mathrm{~min}$. In addition they drank hot tea containing $0.5 \mathrm{~g}$ aspirin. The normal response consists of the appearence of a black-blue colour produced by the starch-iodine reaction. The response is considered abnormal when there is absent sweating and unchanged skin colour.

A skin biopsy was taken from the outer aspect of the thigh and from the forearm. The biopsy was performed using a 6-mm punch following local anaesthesia with $2 \%$ xylocaine and the material obtained was fixed in $15 \%$ calcium formaldehyde for aniline and argentic staining.

Winkelman's method [14] was used to examine the nerve fibres in the skin. In each biopsy, 15-20 sections were examined. A mean number of $50-60$ nerves fibres were studied in each section with particular reference to the dermal-hypodermal junction. Two histopathologists (EF and IC) assessed each biopsy independently, without knowledge of the patients' details or site of biopsy. Nerve fibre morphology was considered normal or abnormal according to our previously published criteria [15-17].

\section{Results}

The Minor test showed that nine of the 11 subjects studied had evidence of anhidrosis in the lower part of the body (Table 1). All the patients showed a normal sweat response in the forearm. In all nine cases with abnormal test, skin biopsies showed morphological abnormalities in the sympathetic nerve fibres which control sweat secretion. These alterations were found in isolated fibres (Fig. 1), in groups of nerves (Fig. 2) and in terminal endings surrounding the sweat glands (Fig.3). These alterations were particularly found in the dermal-hypodermal junction, where sympathetic nerve fibres are more abundant [18-21]. The abnormalities included hyperargentophilia (Fig. 2) and alteration of the calibre and fragmentation of the fibres (Fig. 3). The most severe alterations were found near the sweat glands (Fig. 3). There was no difference found between the histological changes in the nerves of the spontaneous anhidrotic patients (Fig. 1) and those of the two previously sympathectomized patients.

In the histological sections considered as abnormal, the prevalence of fibres damaged was between $25 \%$ and $40 \%$ of the total number of nerves examined.

In the skin biopsies from the thigh taken from the two diabetic patients with normal sweat responses to the Minor test and in all the biopsies from the forearm from all 11 patients studied, no morphological alterations were found in the isolated fibres, (Fig. 4) the nerves (Fig.5) or in the terminal endings near the sweat glands (Fig. 6).

\section{Discussion}

We have shown that the sympathetic nerve fibres which control sweat glands are damaged in diabetics with the anhidrotic syndrome. This confirms the idea that alterations in sweating in diabetics are due to autonomic neuropathy [3-4].

The histological findings must be considered in relation to the whole clinical picture. In the anhidrotic syndrome there is usually preservation of the normal sensitivity of the skin. In keeping with this, the histological abnormalities are localized to the sympathetic nerves. However, it is very difficult to differentiate sympathetic nerves from other sensory nerves in the skin. The former lie in the dermo-hypodermic layer parallel to the skin surface and they are the most abundant nerves in the skin [20-21]. In contrast, the 


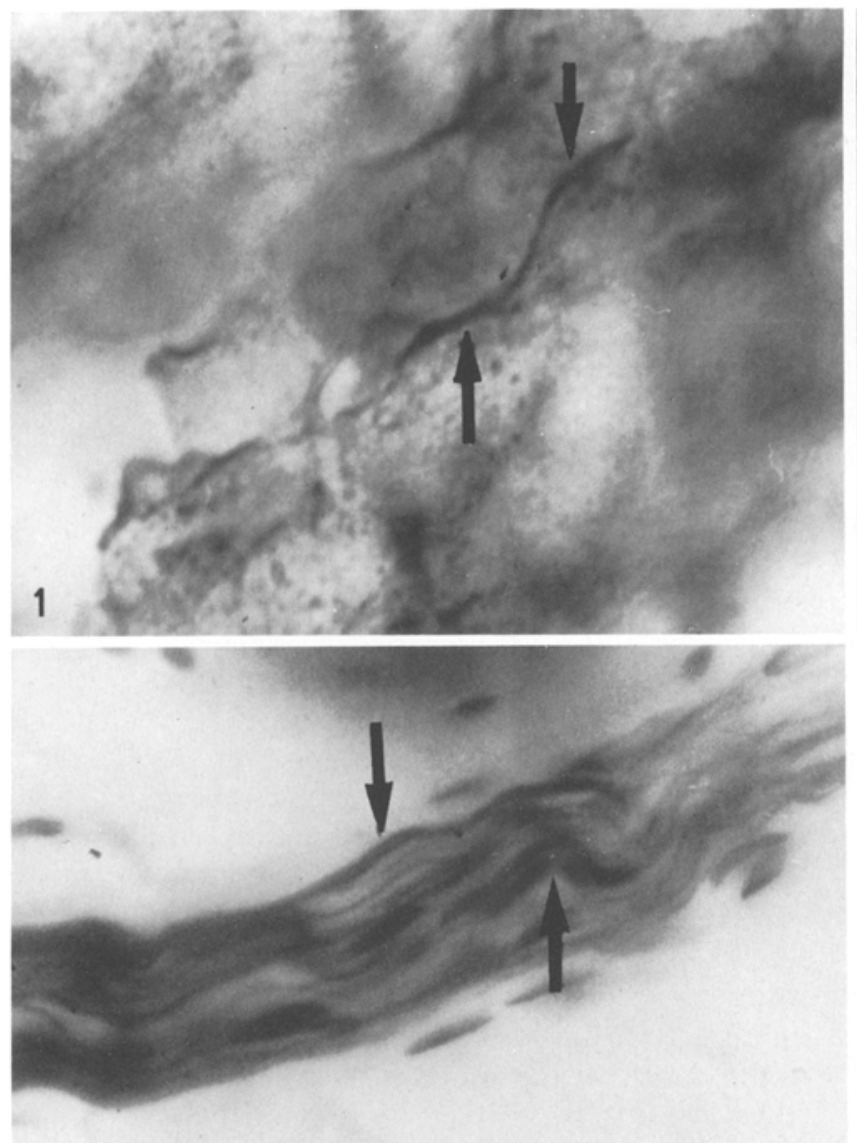

2

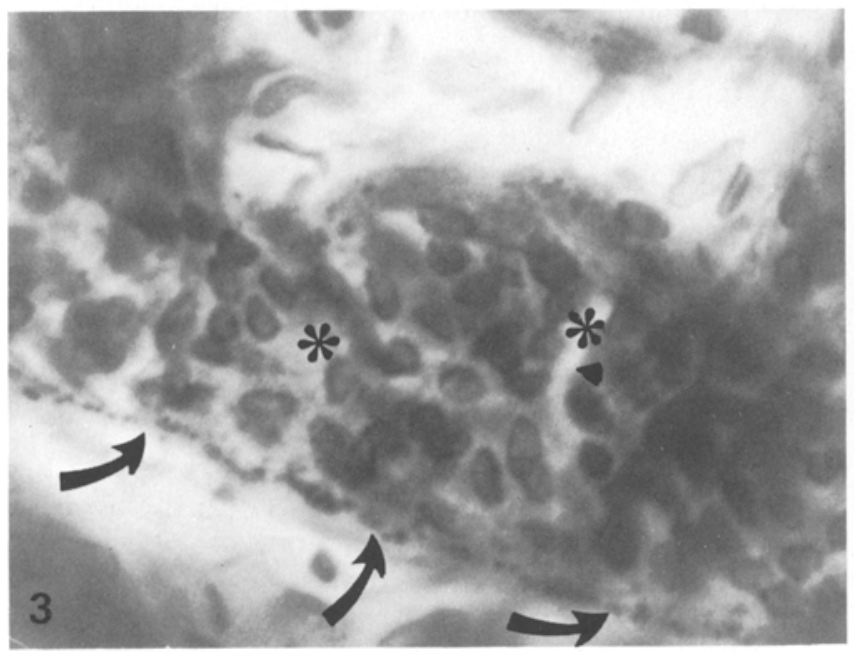

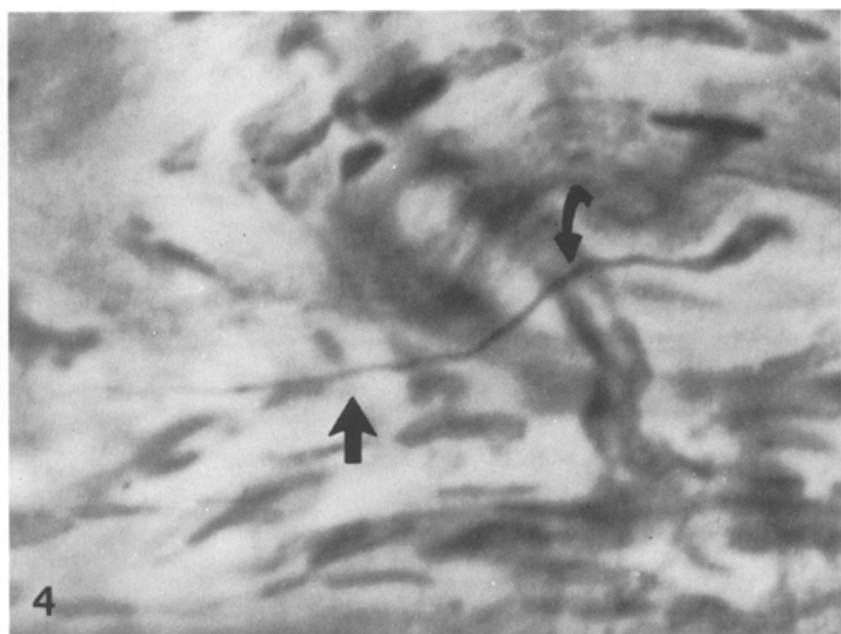
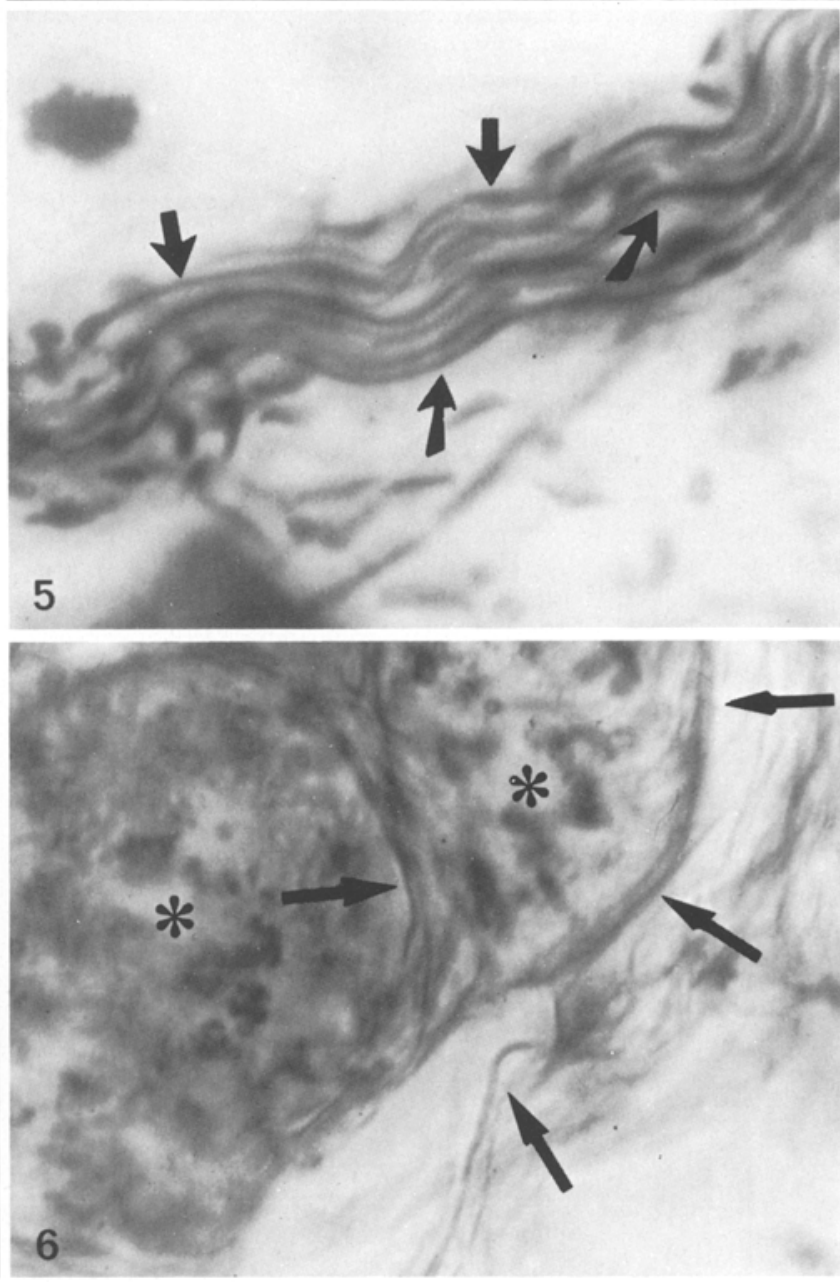

Fig. 1. Abnormal nerve fibre from the thigh in an anhidrotic area. Abnormal calibre, with hyperargentophilia and partial thickening (arrows)

Fig. 2. A bundle of nerves in an anhidrotic area of the thigh in the dermo-hypodermic zone. In the upper part, an abnormal nerve fibre with beaded thickening and spindle-shaped aspect (arrow) and in the lower part, two abnormal beaded fibres with hyperargentophilia, ending in two thin fibres (arrow)

Fig. 3. A sweat gland $(*)$ from an anhidrotic area in the thigh of a diabetic patient. There are relatively few nerve fibres surrounding the gland. They are fragmentated, appearing as argentophilic spherical swellings (arrows)

Fig. 4. Normal aspect of an isolated nervous fibre from the forearm with normal sweat response. Note the regular and thin caliber and impregnation (arrow). The fibre is finishing in a connective cell (in contrast with Fig. 1)

Fig. 5. Normal appearence of a nerve from the forearm of a subject with a normal sweat response to the Minor test, showing the dermohypodermic junction of the skin (arrows). Note the number of fibres, the thin calibre with normal staining (in contrast to Fig. 1)

Fig. 6. A group of normal sweat glands ( $\left.{ }^{*}\right)$ from the forearm of a subject, with a normal sweat response to the Minor test. They are surrounded by a group of normal nerve endings (arrows) and in the lower part, an isolated nerve fibre is approaching the gland (arrow) (in contrast to Fig. 3) 
other sensory nerves tend to run perpendicular to the skin surface and are located in the superficial layers including the epidermis [21].

We wish to emphasize that in two patients (patients 6 and 10, Table 1) a surgical sympathectomy had been performed prior to the present study. We could not differentiate the histological abnormalities in these cases from those found in the patients with the spontaneous anhidrotic syndrome. We can only speculate whether the histological lesions were due to sympathectomy or to previous autonomic neuropathy. However, these findings emphasize the point that sympathectomy is unlikely to provide any benefit to patients who have evidence of the anhidrotic syndrome or in those subjects who have a defective response to the Minor test or other forms of sweat provocation.

A number of papers have been published which stressed [22-24] the high failure rate of sympathectomy operations in diabetics. We believe that the failure of the operation is due to the fact that diabetic autonomic neuropathy has already sympathectomized the patient. The results of the present study are compatible with this idea. It is also of interest that the histological abnormalities found in the present study are similar to those described in the bladder [15], in the corpora cavernosa [16] and in the myocardium [17], all of which are typical sites of diabetic autonomic neuropathy. Thus, autonomic neuropathy is a very common feature in diabetes and an important background to the development of other complications. For example, although the chronic dryness of the skin is rarely troublesome for the patient, it may lead to skin shrinkage and cracking which may, in turn, predispose to infection.

Acknowledgements. The authors would like to thank Mrs. H. Fabricant for translating into English and reviewing the manuscript, Dr. S.L.de Faerman for her constant and valuable help and Mrs. G. Méndez de Grassi for typing the manuscript.

\section{References}

1. Faerman I, Jadzinsky MN, Podolsky S (1980) Diabetic neuropathy and sexual dysfunction. In: Podolsky S (ed) Clinical diabetes. Modern management. Appleton-Century-Crofts, New York, pp 293-340

2. Pryce TD (1893) On diabetic neuritis, with a clinical and pathological description of three cases of diabetic pseudotabes. Brain $16: 416-424$

3. Rundles RW (1945) Diabetic neuropathy, general review with report of 125 cases. Medicine 24: 111-160

4. Odel HM, Roth G, Keating FR (1955) Autonomic neuropathy simulating the effects of sympathectomy as a complication of diabetes mellitus. Diabetes 4:92-98

5. Goodman JI (1966) Diabetic anhydrosis. Am J Med 41: 831-835

6. List CF, Peet MM (1938) Sweat secretion in man. Arch Neurol Psychiatr 39: 1228-1237
7. Hyndman DR, Wolkin J (1941) Sweat mechanism in man: study of distribution of sweat fibres from sympathetic ganglia, spinal roots, spinal cord and common carotid artery. Arch Neurol Psychiatr 45: 446-467

8. Minor V(1927) Ein neues Verfahren zu den klinischen Untersuchungen der Schweißabsonderung. Dtsch Z Nervenheilkde 101:302-308

9. Brown GE, Adson AW (1929) Physiologic effects of thoracic and lumbar sympathetic ganglionectomy or section of trunk. Arch Neurol Psychiatr 22:322-357

10. Guttman L (1947) Management of the quinarizine sweat test. Postgrad Med J 23: 353-366

11. Montagna W, Parakkal P (1974) The structure and function of the skin. Academic Press, New York, pp 121, 157-159

12. Iñiguez RA, Rebollo MA (1967) Neuroanatomía. Intermédica, Buenos Aires, pp 314-315

13. Shumacker HB Jr (1942) Sympathetic denervation of feet and legs occurring spontaneously or as a result of disease : a preliminary report. Bull John Hopkins Hosp 71: 1-17

14. Winkelman R (1971) New methods for the study of nerve endings. In: Helwig EB (ed) The skin. International academy of pathology monograph. Williams and Wilkins, Baltimore, pp $112-127$

15. Faerman I, Glocer L, Celener D, Jadzinsky MN, Fox D, Maler M, Alvarez E (1973) Autonomic nervous system and diabetes: Histological and histochemical study of the autonomic nerve fibers of the urinary bladder in diabetic patients. Diabetes 22 : 225-237

16. Faerman I, Glocer L, Fox D, Jadzinsky MN, Rapaport M (1974) Impotence and diabetes. Histological studies of the autonomic nervous fibers of the corpora cavernosa in impotent diabetic males. Diabetes 23:971-976

17. Faerman I, Faccio E, Milei J, Núñez R, Jadzinsky MN, Fox D, Rapaport N (1977) Autonomic neuropathy and painless myocardial infarction in diabetic patients. Diabetes $26: 1147-1158$

18. Bourlond A (1968) L'innervation cutanée. Masson, Paris, p 81

19. Bourlond A, Winkelmann RK (1966) Nervous pathways in papillary layer of human skin: an electron microscopy study. J Invest Dermatol 47: 193-204

20. Pinkus H (1971) Embriology and anatomy of skin. In: Helwig EB (ed) The skin. International academy of pathology monograph. Williams and Wilkins, Baltimore, pp 1-27

21. Winkelman RK (1967) Cutaneous nerves. In: Zelickson AS (ed) Ultrastructure of normal and abnormal skin. Lea and Febiger, Philadelphia, pp 202-227

22. Shuman Ch, Podolsky S (1980) Surgery in the diabetic patient. In: Podolsky S (ed) Clinical diabetes - modern management. Appleton-Century-Crofts, New York, pp 509-535

23. Haimovici H (1971) Peripheral arterial disease in diabetes mellitus. In: Ellenberg M, Rifkin H (eds) Diabetes mellitus - theory and practice. McGraw-Hill Book Co, New York, pp 890-911

24. Faerman I, Lacour R, Brenner E, Garibaldi I, Grinspan D (1979) Interdisciplinary team-work in the treatment of foot lesions in diabetic patients (abstract). In: Waldhäusl W, Alberti KGM (eds) 10th IDF Congress ICS, No. 481. Excerpta Medica, Amsterdam, pp 60, 152

Received: 20 March 1981

and in revised form:9 September 1981

Isaac Faerman, M.D

Endocrine and Diabetes Section

Department of Medicine

Hospital Español

Aráoz 2663 - piso $5^{\circ}$

1425 Buenos Aires, Argentina 